http://jmscr.igmpublication.org/home/ ISSN (e)-2347-176x ISSN (p) 2455-0450 crossref DOI: https://dx.doi.org/10.18535/jmscr/v9i1.48

\author{
Dournal Of Medical Science And Clinical Research \\ IGM Publication \\ An official Publication of IGM Publication
}

\title{
Case Report \\ COVID 19 with HIV Infection - Dual infection- Is it on your timeline already or still a long hauler?
}

\author{
Authors \\ Urvashi Khan ${ }^{1}$, Anil Kumar ${ }^{2}$ \\ ${ }^{1} \mathrm{MD}$ (Medicine), Post Graduate Resident, Department of Medicine, Santosh Medical College \& \\ Hospitals.GZB UP \\ ${ }^{2}$ DNB, IDCCM, IFCCM, MNAMS, Senior Consultant and Head, Department of Critical Care Medicine, \\ Santosh Medical College \& Hospitals.GZB UP \\ Corresponding Author
}

Dr Anil Kumar

\section{Background}

The COVID 19 has been a severe pandemic all around the world. Nowadays the patient with co infection of HIV with SARS CoV 2 was rarely reported. Here we report a special case of HIV and SARS CoV 2 co infection which was accidentally diagnosed and had a very fast deterioration in her clinical condition. COVID 19 is a novel corona virus disease with over 3,72,32,322 confirmed cases worldwide. ${ }^{1}$ The knowledge regarding epidemiology and clinical presentation have been evolving gradually in the past months since the initial identification. In the general population, the reported case fatality rate is $3.4 \%$ in different countries. ${ }^{2}$ The concern over the increasing risk of severe COVID-19 disease with patients diagnosed with HIV may be based on the assumption that PLHIV are more likely to be immunosuppressed. HIV infection is associated with abnormal humoral and T-cell-mediated immune responses, resulting in increased susceptibility to numerous opportunistic infections. ${ }^{3}$ Here we are reporting a case of HIV and SARS CoV 2 co infection who presented with a mild dyspnea and fever and later progressed to fast deterioration.Given the urgency of the COVID-19 pandemic and the rapidly changing information about the disease, a high degree of vigilance is needed on the course of infection among PLHIV. As there are 37.9 million PLHIV and 1.7 million new infections each year ${ }^{4}$, patients of COVID-19-HIV co-infection are likely to increase with varied level of clinical presentation and severity.

\section{Case Report}

A 39 years old female presented to emergency department with complaints of high grade fever since 4 days accompanied by mild dyspnea, oral ulcers and asthenia and COVID 19 RTPCR positive report. She had no contact history to any COVID patient and no significant travel history. The initial physical examination revealed a body temperature of $101.4 \mathrm{~F}$, oxygen SPO2 88-90\% on room air, respiratory rate of 24 breaths/minute, 
blood pressure of 138/80 $\mathrm{mmHg}$, and pulse of 110 bpm. Investigation were suggestive of marked pancytopenia. Patient was accidentally diagnosed to have HIV. On detailed history it was found that patient's husband was living with HIV since 2 years and had been on antiretroviral treatment. We started the patient on anti-SARS-CoV-2 treatment administered with broad spectrum antibiotics, anticoagulant, corticosteroids, antivirals. Chest $\mathrm{x}$ ray done on admission showed clear lung fields and no significant abnormalities.

Patient was kept under observation in High dependency unit where patient's fever started to resolve along with decreased tachypnea. She denied fever, shortness of breath, chest pain, only cough persisted. Patient's xray was repeated to see any developing pneumonia but it remained clear.
Suddenly on day $5^{\text {th }}$ patient started to complain dyspnea at rest and desaturation was noted followed by tachypnea and altered sensorium, patient had to be immediately shifted to ICU. All the baseline investigations were repeated and patient was kept on NIV support.

On day $6^{\text {th }}$ the patient's condition further deteriorated and the clotting factors were deranged beyond normal range, tachycardia, hypotension and patient was transfused 4 Fresh frozen plasma due to oral bleeding which was significant.

On day $7^{\text {th }} \times$ ray was suggestive of ARDS with severe metabolic acidosis in the blood gas analysis. Patient was intubated and treatment optimised to maximum support, but despite all the efforts to save the patient, patient succumbed to disease on ninth day.

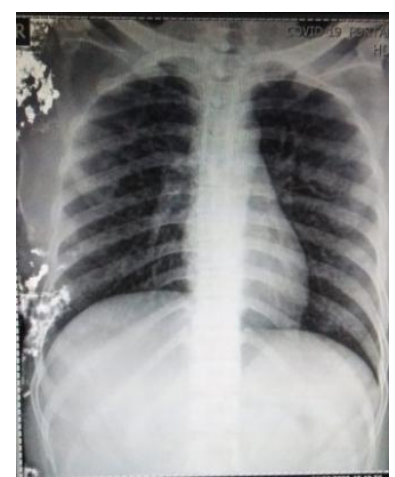

DAY-1

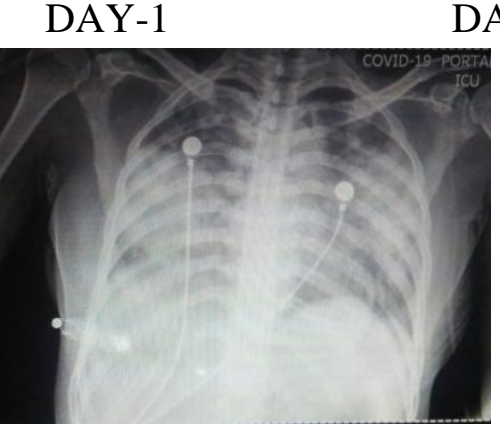

DAY-7

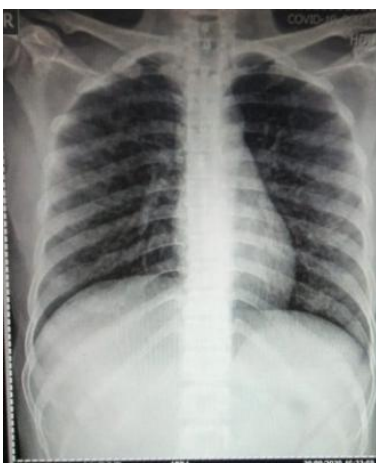

DAY-4

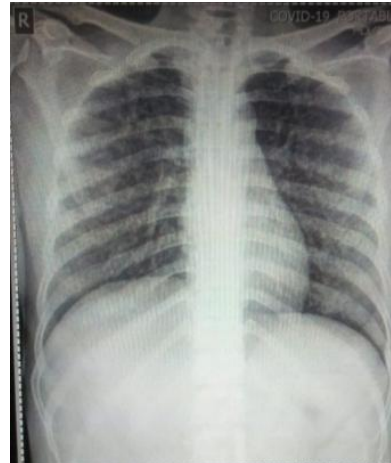

DAY-5

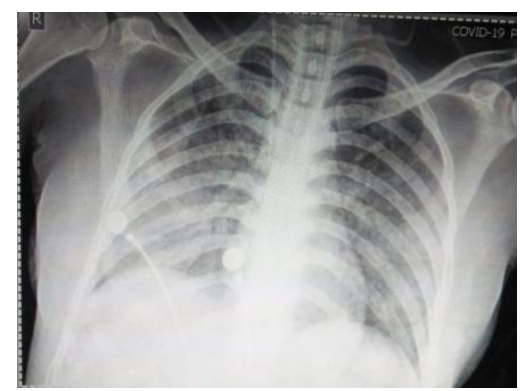

DAY-8

\begin{tabular}{|c|c|c|c|c|c|}
\hline & DAY-1 & DAY-4 & DAY-5 & DAY-7 & DAY-8 \\
\hline TEMP(F) & 101.4 & 100 & 98.8 & 99.8 & 98.6 \\
\hline SYMPTOMS & $\begin{array}{l}\text { Fever, cough, malaise, } \\
\text { headache, oral ulcers }\end{array}$ & $\begin{array}{c}\text { Fever, cough, } \\
\text { malaise, headache, } \\
\text { oral ulcers }\end{array}$ & $\begin{array}{c}\text { Cough, } \\
\text { malaise, } \\
\text { Dyspnea }(2-3)\end{array}$ & $\begin{array}{c}\text { Cough, } \\
\text { malaise, } \\
\text { Dyspnea(3-4) }\end{array}$ & $\begin{array}{c}\text { Fever, cough, } \\
\text { Dyspnea(4) }\end{array}$ \\
\hline $\mathrm{BP}(\mathrm{mmHg})$ & $138 / 80$ & $140 / 90$ & $120 / 76$ & $100 / 60$ & $90 / 60$ \\
\hline $\mathrm{RR}(\mathrm{cpm})$ & 24 & 22 & 24 & 30 & 38 \\
\hline HR(bpm) & 110 & 96 & 100 & 122 & 130 \\
\hline O2 sat(\%) & $88-90$ & $91-94$ & $91-94$ & $80-85$ & 70 \\
\hline CXR findings & Normal & Normal & $\begin{array}{l}\mathrm{B} / \mathrm{L} \text { basal } \\
\text { infilterates }\end{array}$ & ARDS & $\begin{array}{c}\mathrm{B} / \mathrm{L} \\
\text { pneumonitis }\end{array}$ \\
\hline TLC & 1980 & & & 4450 & 12480 \\
\hline Lymphocytes & 4 & & & 3 & 2 \\
\hline
\end{tabular}




\begin{tabular}{|l|c|c|c|}
\hline Platelets & 0.70 & & 0.90 \\
\hline ABG & $\begin{array}{c}\text { Respiratory } \\
\text { alkalosis(partially } \\
\text { compensated) }\end{array}$ & $\begin{array}{c}\text { Severe } \\
\text { metabolic } \\
\text { acidosis. } \\
\text { acidosis } \\
\text { (partially } \\
\text { compensated) }\end{array}$ \\
\hline LDH/CRP/PT/INR/ & $398 / 28 / 16 / 1.18 /$ & $450 / 48 / 1.68 / 0.5$ & $30.1 / 2.34$ \\
D-DIMER/ & $0.43 /$ & $540 / 370 /$ & $40 / 0.6$ \\
Ferritin/Fibrinogen/apt/ & $/ 480 / 350 / 39 / 0.5$ & & \\
PCT & & & \\
\hline
\end{tabular}

\section{Discussion}

In our case, oral ulceration, pancytopenia and rapid clinical deterioration along with history of husband HIV positive and on treatment, raised the suspicion of HIV disease, which was later found to be positive. Our patient had Significant detioration which could be due to HIV along with severe immune suppression, covid sequalae likely pulmonary embolism, worsening sepsis with MODS or any thrombotic complication. Nowadays, the COVID-19 has been a worldwide pandemic disease. As an pandemic disease, viral shedding duration is the key to disease control. Some studies found asymptomatic people who were still carrying the virus after isolation for 14 days $^{5}$. There are recent evidences which raises concerns on using HCQs to treat the case ${ }^{6}$. Further studies and data collection are needed for this. In our case, the patient had a history of fever and had findings of developing pneumonia. COVID-19 was diagnosed by the positive result of RT-PCR.

$\mathrm{Xu}$ et al. ${ }^{7}$ concluded the risk factors of prolonged viral RNA shedding in COVID-19 patients: male sex, delayed admission to hospital after illness onset, and invasive mechanical ventilation. These risk factors cannot explain the prolonged duration of the patient in our report. Qin et al. ${ }^{8}$ reported that the total number of B cells, T cells, and NK cells decreased significantly in patients with COVID-19. And the sum of lymphocytes of the severe group dropped more significantly than the moderate group. So, the infection of SARS-CoV-2 might be dramatically for the people living with HIV. On the one hand, the immune system might be impaired after the infection of SARS-CoV-2 by the depletion of $\mathrm{T}$ lymphocytes ${ }^{8}$. On the other hand,during the chronic phase of HIV infection, generalized immune activation, and systemic CD4+ T lymphocyte depletion occur ${ }^{9}$.

Coinfection with HIV and SARS-CoV-2 does not appear to worsen COVID-19 infection outcomes. The greatest number of complicated COVID-19 cases occurs in patients with chronic disease comorbidities, such as hypertension, diabetes, and cancer, in addition to those older than 60 years. However, the evidence is not sufficient to indicate whether mortality in patients with a severe immunosuppressed state is higher or lower ${ }^{10}$. For example, a study by Guo et al. ${ }^{11}$ in China concluded that the incidence of COVID-19 in people living with HIV is comparable to that of the general population. In addition, this study indicated that low CD4+ levels and high levels of viral load influence the lethal progression of COVID-19. For their part, Harter et al. ${ }^{10}$ in Germany documented that of 32 patients with double infections of HIV and SARS-CoV-2, only $9 \%$ died and $76 \%$ of these cases were reported as mild. Despite these findings, Vizcarra et al. ${ }^{12}$ in Spain suggest that people living with HIV should not consider themselves protected from SARS infection-CoV-2 or having a lower risk of serious disease. In fact, there are not yet enough data to test or rule out this hypothesis. ${ }^{13}$ More recently, Gervasoni et al. ${ }^{14}$ in Italy, found a $96 \%$ survival of HIV patients with SARS-CoV-2 coinfection. They argued that ART may have played a role in the positive evolution of COVID-19 in their patient study group. In fact, Del Amo et al. ${ }^{15}$ in Spain demonstrated that ART based on nucleotide reverse transcriptase inhibitors may protect patients from acquiring COVID-19. They noted that those HIV patients receiving tenofovir disoproxil fumarate (TDF)/emtricitabine (FTC) had a lower risk for COVID-19 and related 
hospitalizations than those receiving other ART drugs.

\section{Why this case report?}

Our understanding of the risk of developing Severe COVID 19 in people living with HIV is still evolving. There are few case reports on Covid 19 and HIV and few studies to accomplish the relation of the severity of this virus in people who are infected and how the disease behaves.

\section{Conclusion}

We found superimposed bacterial pneumonia with COVID-19 with HIV. These patients generally had poorer outcomes irrespective of controlled HIV or AIDS. Blanco et al. ${ }^{16}$, described a case of Pneumocystis jirovecii in a patient with AIDS and COVID-19 which responded well to antibiotics. They raised the issue of ensuring that pulmonary opportunistic infections are considered in the differential diagnoses of SARS-CoV-2 and HIV co-infection, particularly in AIDS patients. This was supported by Karmen-Tuohy et al. ${ }^{17}$, who found three patients with HIV and COVID-19 developed superimposed non-AIDS related bacterial pneumonia, compared to only one HIV negative patient with COVID-19. All of the patients who developed a superimposed bacterial pneumonia died in this study, despite receiving antibiotic treatment. Whilst this is a small cohort of patients, it highlights potentially worse outcomes for patients who have a superimposed bacterial pneumonia with COVID-19. Patients with HIV show a higher incidence of bacterial pneumonia, which is inversely proportional to CD4 T-Cell count, when compared to the general population. Thus, superimposed bacterial pneumonia with COVID-19 is a significant consideration in PLHIV $^{18-22}$. Our case report highlights the importance of identifying coinfections, addressing co-morbidities, and ensuring a secure supply of ART for PLHIV during the COVID-19 pandemic. The 14 days isolation strategy might not be long enough for them. These patients need further evaluation along with stringent clinical support and monitoring to improve disease outcomes and quality of life.

\section{References}

1. WHO Coronavirus disease situation reports. 2020. https ://www.who.int/.

2. Ciotti MA, Minieri S, Giovannetti M, Benvenuto M, Pascarella DS, Sagnelli C, Bianchi M, Bernardini S, Ciccozzi M. COVID-19 outbreak: an overview. Chemotherapy. 2020;64:1-9

3. Chang CC, Crane M, Zhou J, Mina M, Post JJ, Cameron BA, Lloyd AR, Jaworowski A, French MA, Lewin SR. HIV and co- infections. Immunological reviews. $2013 \mathrm{Jul} ; 254(1): 114-42$.

4. Mahy M, Marsh K, Sabin K, Wanyeki I, Daher J, Ghys PD. HIV estimates through 2018: data for decision-making. AIDS (London, England). 2019 Dec 15;33(Suppl 3):S203.

5. Mao ZQ, Wan R, He LY, Hu YC, Chen $\mathrm{W}$. The enlightenment from two cases of asymptomatic infection with SARS-CoV2: is it safe after 14 days of isolation? Int $\mathbf{J}$ Infect Dis. 2020;95:174-5.

6. Cavalcanti AB etal.,2020. Hydroxychloroquinew with or without azithromycin in mild-to-moderate COVID19. N Engl J Med.

7. Xu K, Chen Y, Yuan J, Yi P, Ding C, Wu $\mathrm{W}$, et al. Factors associated with prolonged viral RNA shedding in patients with COVID-19. Clin Infect Dis. 2020. https ://doi.org/10.1093/cid/ciaa3 51.

8. Qin C, Zhou L, Hu Z, Zhang S, Yang S, Tao $\mathrm{Y}$, et al. Dysregulation of immune response in patients with COVID-19 in Wuhan, China. Clin InfectDis.2020. https://doi.org/10.1093/cid/ciaa2 48

9. Mahnke YD, Fletez-Brant K, Sereti I, Roederer M. Reconstitution of peripheral $\mathrm{T}$ cells by tissue-derived CCR $4+$ central memory cells following HIV-1 
antiretroviral therapy. Pathog Immun. 2016;1(2):260-90.

10. Harter G et al., 2020. COVID-19 in people living with human immunodeficiency virus: a case series of 33 patients. Infection $1-6$.

11. Guo W, Fangzhao M, Dong Y, Zhang Q, Zhang X, Mo P, Feng Y, Liang K, 2020. A survey for COVID-19 among HIV/AIDS patients in two districts of Wuhan, China. SSRN.

12. Vizcarra P, Perez-Elias MJ, Quereda C, Moreno A, Vivancos MJ, Dronda F, Casado JL, Team C-I, 2020. Description of COVID-19 in HIV-infected individuals: a single-centre, prospective cohort. Lancet HIV 7: e554-e564.

13. Xu Z, Zhang C, Wang FS, 2020. COVID19 in people with HIV. Lancet HIV 7: e524-e526.

14. Gervasoni C, Meraviglia P, Riva A, Giacomelli A, Oreni L, Minisci D, Atzori C, Ridolfo A, Cattaneo D, 2020. Clinical features and outcomes of HIV patients with coronavirus disease 2019. Clin Infect Dis ciaa579.

15. Del Amo J, Polo R, Moreno S, Diaz A, Martinez E, Arribas JR, Jarrin I, Hernan MA, 2020. Incidence and severity of COVID-19 in HIV-positive persons receiving antiretroviral therapy: a cohort study. Ann Intern Med 173: 1-8.

16. Blanco JL, Ambrosioni J, Garcia F et al. COVID-19 in patients with HIV: clinical case series. The Lancet HIV 2020;7: e314e316.

17. Karmen-Tuohy S, Carlucci PM, Zacharioudakis IM et al. Outcomes among HIV-positive patients hospitalized with COVID-19. Med Rxiv. Available at https://www.medrxiv.org/content/10.1101/ 2020.05.07.20094797v1 (accessed 18 May 2020).
18. Cill_oniz C, Garc_1a-Vidal C, Moreno A, Miro JM, Torres A. Community-acquired bacterial pneumonia in adult HIV infected patients. Expert Rev Anti Infect Ther 2018; 16: 579-88.

19. Feikin DR, Feldman C, Schuchat A, Janoff EN. Global strategies to prevent bacterial pneumonia in adults with HIV disease. Lancet Infect Dis 2004; 4: 445-455.

20. Søgaard OS, Reekie J, Ristola M et al. Severe bacterial non aids infections in HIV-positive persons: incidence rates and risk factors. J Infect 2013; 66: 439-446.

21. Kohli R, Lo Y, Homel P et al. Bacterial pneumonia, HIV therapy, and disease progression among HIV-infected women in the HIV epidemiologic research (HER) study. Clin Infect Dis 2006; 43: 90-98.

22. Croxford S, Kitching A, Desai $\mathrm{S}$ et al. Mortality and causes of death in people diagnosed with HIV in the era of highly active antiretroviral therapy compared with the general population: an analysis of a national observational cohort. Lancet Public Health 2017; 2: e35-e46. 